\title{
A performance da folia de São Sebastião na Comunidade Quilombola Magalhães
}

\section{The performance of the São Sebastião revelry in the Quilombola Magalhães Community La actuación de la fiesta de São Sebastião en la comunidad de Quilombola Magalhães}

Reigler Siqueira Pedrozaa,* (D), Rosirene Campêlo dos Santos ${ }^{a}$ (D), Dulce Maria Filgueira de Almeidab (D)

Palavras-chave
Corpo;
Grupos étnicos;
Folia;
Performance cultural.

Performance cultural.

\section{Keywords}

Body;

Éthnic groups;

Revelry;

Cultural performance.

Palabras clave

Cuerpo;

Grupos étnicos;

Jolgorio;

Actuación cultural.

\begin{abstract}
RESUMO
Esta pesquisa analisou os aspectos simbólicos do ritual de Folia de São Sebastião da Comunidade Quilombola Magalhães. Valeu-se de uma perspectiva etnográfica para interpretar as performances dos foliões, entendidas como técnicas corporais eficazes e simbolicamente prestigiosas que se ancoram nas tradições do grupo social. A folia é um ritual caracterizado pela dádiva, na qual suas trocas/intercâmbios ocorrem através do símbolo na sua menor unidade, ou seja, a bandeira. Nessa folia, a bandeira não é uma mera representação do santo perante os homens, mas ele em si. A Folia de São Sebastião é uma performance complexa no interior da tradição cultural desta comunidade e que representa as relações de poder, parentesco e afinidade desse grupo familiar.
\end{abstract}

\begin{abstract}
This research analyzed the symbolic aspects of the Folia de São Sebastião ritual of the Quilombola Magalhães Community. It used an ethnographic perspective to interpret the performances of revelers, understood as effective and symbolically prestigious body techniques that are anchored in the traditions of the social group. The revelry is a ritual characterized by the gift, in which its exchanges / exchanges occur through the symbol in its smallest unit, that is, the flag. In this revelry, the flag is not a mere representation of the saint before men, but he himself. The Folia de São Sebastião is a complex performance within the cultural tradition of this community and represents the power, kinship and affinity relationships of this family group.
\end{abstract}

\section{RESUMEN}

Esta investigación analizó los aspectos simbólicos del ritual Folia de São Sebastião de la Comunidad Quilombola Magalhães. Utilizó una perspectiva etnográfica para interpretar las actuaciones de los juerguistas, entendidas como técnicas corporales efectivas y simbólicamente prestigiosas de las tradiciones del grupo social. La juerga es un ritual caracterizado por el regalo, en el cual sus intercambios ocurren a través del símbolo en su unidad más pequeña, es decir, la bandera. En esta juerga, la bandera no es una mera representación del santo ante los hombres, sino él mismo. La Folia de São Sebastião es una actuación compleja dentro de la tradición cultural de esta comunidad y representa el poder, el parentesco y las relaciones de afinidad de este grupo familiar.

aUniversidade Estadual de Goiás, Escola Superior de Educação Física e Fisioterapia do Estado de Goiás. Goiânia, GO, Brasil. bUniversidade de Brasília, Faculdade de Educação Física. Brasília, DF, Brasil.

\footnotetext{
*Autor correspondente:

Reigler Siqueira Pedroza

E-mail: reigler@hotmail.com 


\section{INTRODUÇÃO}

O objeto de estudo desta pesquisa está circunscrito ao corpo-negro-quilombola ${ }^{1}$ e sua expressividade em uma festa religiosa denominada Folia de São Sebastião da Comunidade Quilombola Magalhães, situada no município de Nova Roma/Goiás/Brasil. Aqui o corpo está sendo compreendido para além de uma visão meramente biológica e/ou mecânica, reconhecendo-o como produtor de cultura. Nessa perspectiva, iremos compreendê-lo em rituais cujos processos de transmissão ocorrem por meio da tradição, que, por seu turno, é constantemente (re)inventada na dinâmica cultural. Portanto, a expressividade do corpo se materializa nos rituais de folia de São Sebastião da Comunidade Quilombola Magalhães por meio de performances culturais.

Segundo Mauss (1974, p. 211), as técnicas corporais são as maneiras eficazes "[...] como os homens, de sociedade em sociedade e de maneira tradicional, sabem servir-se de seus corpos". Existe um conjunto de gestos que compõem a educação de nossos corpos que comumente passam despercebidos e que podem ser exemplificados com os atos de sentar, andar, correr, saltar etc. Cada uma dessas técnicas corporais é apreendida de forma distinta nas diversas culturas, a depender do uso social que é dado a cada uma delas.

Neste contexto, a performance é uma ação intencional, seja individual ou coletiva, construída subjetivamente ou racionalmente, dentro da situação ritual. Esta possui um simbolismo verbal (exemplificado na folia pelos cantos e rimas) e outro não verbal (expresso na folia através das coreografias, das danças e nas formas de tocar os instrumentos dando síntese a esta linguagem ou expressividade corporal). Seu simbolismo pode representar tanto a transmissão/reafirmação de valores, hábitos, costumes e normas de um determinado grupo social como também suas intenções de transgressão ou anseios de transformação, evidenciados na polarização do ritual (Turner, 1989). Desta forma, a problemática desenvolvida nesta etnografia valeu-se das performances de "solta", "giro" e entrega" do ritual de Folia de São Sebastião para analisar os aspectos simbólicos do corponegro-quilombola.

\section{POR UMA LEITURA ETNOGRÁFICA DOS PROCESSOS RITUAIS}

Segundo Peirano (1995), a etnografia não se restringe a uma descrição cultural, pois o trabalho de campo permite ao antropólogo construir teoria e pensar a realidade. Portanto, utilizaremos os rituais como possibilidade para descrever e, também, analisar a realidade a qual nos debruçamos. De acordo com Radcliffe Brown (1973), o ritual permite tocar na sensibilidade, pelo fato de ser a expressão simbólica

1 Expressão cunhada pela primeira vez por Oliveira (2018). do sentimento. Nesta perspectiva, nosso olhar estará centrado nas práticas corporais experienciadas pelos indivíduos no processo ritual, pois para Leach (1966) os rituais perpetuam os saberes de uma tradição cultural. Durante um ritual podemos ter tanto a transmissão de valores que legitimam a ordem social, portanto, a estrutura, como também os elementos da anti-estrutura, como nos demonstra Turner (1957). Para que isto ocorra é necessário um período liminar, onde o símbolo se apresenta em seu estado de maior condensação.

Vale mencionar que, de acordo com Turner (2008), o ritual só se opera por meio de símbolos, pois sua existência está por ele condicionada. Os símbolos rituais possuem uma polarização, dividem-se em pólo ideológico (relacionado aos valores e regras sociais do grupo) e o pólo sensorial (relacionado com os prazeres e a negação da ordem social vigente). Observamos as técnicas corporais em situações performáticas, no qual a performance se caracteriza pela improvisação e a capacidade de criação dos sujeitos durante a realização do ritual. A partir do exposto, propomos realizar uma análise dos rituais na Comunidade Quilombola Magalhães com base na tradição cultural expressa nos aspectos simbólicos do corpo.

\section{RESULTADOS E DISCUSSÃO}

A Comunidade Quilombola Magalhães está situada à margem esquerda do rio Paranã e pertence ao município de Nova Roma/GO, na região da Chapada dos Veadeiros. A comunidade teve um laudo antropológico realizado por Almeida (2007), o qual foi anexado ao seu processo de demarcação e titulação das terras a partir do seu reconhecimento em 2004, pela Fundação Cultural Palmares, como comunidade remanescente de quilombo.

Segundo Almeida (2007), a comunidade inicia-se a partir do casamento de Seu Pedro Magalhães da Cunha e de Dona Alvina Pereira dos Santos, em 1944. O esposo é descendente dos Kalunga de Monte Alegre e a esposa era moradora da região (seus pais trabalhavam para um fazendeiro na margem direita do rio Paranã), migrando da parte sul da Bahia. Ambos se fixaram na região do Lavado (nome do córrego que nomeia a localidade onde está situada a comunidade atualmente) e tiveram 11 filhos. De acordo com a genealogia, a família possui 78 membros vivos. Depois de Dona Alvina, na primeira geração, temos 18 pessoas na segunda geração, na terceira, são 39 membros e por último, temos 21 bisnetos/as da matriarca. A família é composta por cerca de 22 grupos familiares (casal e filhos), sendo que a ocupação espacial é determinada pelas relações de afinidade, consanguinidade e, consequentemente, de parentesco.

Com relação aos aspectos culturais do grupo, damos destaque aos quatro rituais/festejos tradicionais realizados ao longo do ano. Para efeito didático, nomearemos de ciclo esse período de um ano que contempla os quatro rituais/festejos da Comunidade Quilombola Magalhães. O primeiro deles, tomando por 
referência os meses do ano, é realizado todo dia 20 de janeiro em homenagem a São Sebastião, cujo responsável é Seu Zé, primeiro filho da matriarca. O segundo possui a duração de 10 dias, de 9 a 19 de julho, é a Folia de São Sebastião, cujo responsável é Seu Loro e Dona Dominga, sobrinho e terceira filha da matriarca, respectivamente. O terceiro ocorre todo dia 12 de outubro para Nossa Senhora Aparecida, sendo responsável Seu Rivalino, décimo primeiro filho da matriarca. Fechando o ciclo e sendo o quarto deles, temos dia 8 de dezembro o ritual/festejo para Nossa Senhora da Conceição, feita pela matriarca da comunidade, a Dona Alvina. O grupo social pratica um catolicismo camponês tradicional, como destaca Almeida (2007), herdado dos rituais/festejos Kalunga da região de Monte Alegre/GO.

A Folia de São Sebastião possui um diferencial em relação aos outros quatro rituais realizados na comunidade, a começar pelo fato de sua tradição não ter começado depois do casamento de Seu Pedro com Dona Alvina, em 1944. O ritual é oriundo de uma tradição de folia dos Kalungas de Monte Alegre/GO, chegando à região através do processo migratório que levou Seu Pedro Magalhães, conjuntamente com seus três irmãos, a essa localidade quando subiram o rio Paranã. Dona Maria Magalhães, irmã de Seu Pedro Magalhães, era a festeira na época e, após sua morte, a tradição da folia passou a ser responsabilidade do seu filho Louriano e sua esposa, Dona Dominga, filha de Pedro Magalhães, sendo ambos, primos de primeiro grau.

Quase sempre as folias são estudadas na cidade e, quando no campo, é raro o pesquisador conviver com os foliões durante todos os dias do ritual, tendendo a acompanhar apenas a solta e a entrega da folia (Brandão, 1981). Nesta etnografia, procuramos seguir o conselho do autor e acompanhamos o ritual desde o seu preparativo até a entrega da Folia de São Sebastião. Dessa forma, foi possível analisar, dentro dos limites colocados pelo trabalho de campo, os aspectos simbólicos da performance desse ritual.

\section{"SAÍDA", "GIRO" E "ENTREGA" DA FOLIA DE SÃO SEBASTIÃO}

A folia se realiza seguindo um processo ritual determinado pela "saída", "giro" e "entrega". Esses três elementos ritualísticos compõem partes de um todo e contribuem para significar a construção do corponegro-quilombola. Suas performances são realizadas por meio de atores sociais que, ao longo do processo ritual, desempenham papéis que detalharemos a seguir.

O festeiro ocupa um papel de centralidade, já que é o herdeiro do ritual e tem a missão de garantir sua periodicidade. Já o promesseiro tem um papel individual e investe em si próprio ou no nome daquele que the custou a dívida junto ao santo. $O$ encarregado é escolhido pelo festeiro logo após a entrega da última folia, é de sua responsabilidade organizar os pousos da folia, os almoços e conseguir o meio de transporte dos foliões. O mestre, assim como o festeiro, tem um papel central, já que possui o maior acúmulo de saberes sobre a folia, é quem conhece toda a estrutura e os elementos constitutivos do rito (os cânticos, as danças e as rezas). Os contramestres são aqueles que respondem/completam os versos cantados pelos mestres. Por último, temos o alfere (aquele que carrega a bandeira do santo devoto) e os devotos-artistas (que tocam os pandeiros e dançam) (Brandão, 1983). O que totalizou dezesseis pessoas envolvidas diretamente com o processo ritual.

No giro da folia de São Sebastião todos os elementos apontados por Brandão (1983) são coincidentes, tanto em relação às personalidades e atores sociais, quanto às etapas ritualísticas. Durante o pouso temos a completude de todas as performances culturais, a saber: o agasalho, o canto para o dono da casa, o bendito de mesa, e, por derradeiro, a sussa, a curraleira e a despedida. No almoço ocorrem apenas três, que são o canto para o dono da casa, o bendito de mesa e a curraleira. Entre o pouso e o almoço e o almoço e o pouso, temos apenas duas, o canto para o dono da casa e a curraleira. Durante os dez dias de giro da folia a bandeira do santo adentrou um total de 77 casas.

Neste ano, a encarregada pela "solta" da folia foi a irmã do prefeito da cidade de Nova Roma/GO. Esta teve a função de organizar todas as condições materiais para a folia e seu giro, já que a entrega é de responsabilidade dos festeiros (Seu Loro e Dona Dominga). Isso implica garantir o transporte dos foliões (a cavalo ou motorizado) de um povoado ao outro, e negociar/definir os locais onde serão realizados os "almoços" e, principalmente, os "pousos". Por conta dessas incumbências, o encarregado acaba estabelecendo, seja de forma direta ou indireta, aproximações com os povoados da região durante o exercício do seu ofício, o que possibilita mediar interesses políticos locais. Assim, por ser do grupo familiar responsável pela folia, pode-se verificar as relações políticas e os interesses sociais que se constroem em volta do ritual (Gluckman, 1966). Isso representa, segundo Brandão (2004), uma metáfora/alusão ao poder executivo relacionado à personalidade social do ritual.

A solta da folia foi realizada à noite na casa da encarregada que fica localizada na cidade de Nova Roma/GO, local onde se realizaram os ensaios das performances, os foliões afinaram os instrumentos e definiram os papéis sociais de cada um deles durante o processo ritual. Na manhã seguinte o caixeiro começou a realizar uma batida ritmada que anunciou o início do giro da Folia de São Sebastião daquele ano, momento em que o alfere começou a vestir sua indumentária: paletó de cor bege, um chapéu e uma estola. Foi então quando alçou a bandeira na porta da casa e todos os foliões the acompanharam iniciando o giro da folia. Vale mencionar que um dos autores do artigo foi designado como tendo a função de devoto-artista.

Ao se locomoverem pela cidade, o alfere parou diante da primeira casa que constituía a folia daquele 
ano. Como parte da ritualística, a dona da casa recebe a folia, beija a bandeira e faz o sinal da cruz. Em seguida, enquanto a mulher passava com a bandeira nos cômodos da casa com a finalidade de limpeza e purificação do local, os foliões se organizavam na sala para fazer o "canto para o dono da casa". A dona da casa entregou novamente a bandeira para o alfere que ficou posicionado de frente aos guias, tendo diante dele os moradores da casa. Há uma estrutura hierárquica definida, os mais velhos se posicionam à frente e as crianças, por ordem de idade, ficam mais atrás. Terminado o "canto para o dono da casa", a senhora pegou a bandeira e a guardou num dos cômodos da casa, já os foliões sentaram-se na sala ou na porta da casa para esperar o "agrado". Este nada mais é que um lanche (biscoito, bolo e pão) juntamente com uma bebida (água, café, suco, refrigerante ou pinga).

Durante o momento em que os foliões se alimentam e conversam com vizinhos e conhecidos da região verifica-se que as pessoas mais velhas da casa, conhecedoras do símbolo ritual da bandeira, estabelecem uma ligação mais singular com o polo ideológico, isto é, aquele relacionado aos valores e regras sociais do grupo (Turner, 2008). É o momento da troca, já que os donos da casa ofertaram o alimento e as esmolas para o "canto" que foi realizado pelos foliões e, adquirem, portanto, o direito de agradecer as graças recebidas e fazer novos pedidos, que deverão ser atendidos pelo santo. Passados alguns minutos, o alfere chamou os foliões para cantarem a brincadeira (curraleira) para que pudessem seguir pelas casas, o que foi realizado. Esta estrutura com duas performances por casa se seguiu até o almoço, em que se acrescentaria o bendito de mesa.

O bendito de mesa é composto por duas partes, uma que ocorre antes dos foliões almoçarem e outra depois do almoço. Na primeira parte, os foliões ficam ao redor da mesa, sem o uso do chapéu, e fazem todos juntos o canto de louvor, agradecimento e reconhecimento de Jesus Cristo como Senhor e consolador. São cânticos, isto é, cantos de louvor, versados a partir da história da criação do mundo, morte e ressurreição de Jesus Cristo. Na sequência, os foliões, os expectadores e os donos da casa serviram-se e almoçaram. Após meia hora, o alfere pede ao dono da casa que busque a bandeira e ao caixeiro para tocar o instrumento. $\mathrm{O}$ som da caixa, nesse momento, avisa aos foliões que devem cumprir uma "obrigação" e que se reúnam rapidamente em volta da mesa para cantarem a segunda parte do "bendito de mesa".

Na finalização do bendito de mesa após a realização de cinquenta e seis estrofes do cântico, se observa que a segunda parte da performance se caracteriza pelo agradecimento dos foliões em nome do santo e da comida que lhes foi ofertada. No entanto, há aqui uma reciprocidade, como nos atesta Mauss (1974), em que os foliões agradecem em nome do santo o almoço e o santo possui a obrigação de retribuir aos donos da casa essa graça através da fartura do alimento para a família.
Analisando a completude do cântico, percebemos que os foliões, primeiro, agradecem ao santo pela comida, ao tempo em que pedem proteção para continuarem suas obrigações no giro da folia. Num segundo plano, intercedem à divindade em nome dos donos da casa, seguidos pelas cozinheiras e pelos expectadores. $\mathrm{Na}$ sequência, como de costume, tivemos a performance da sussa, que corresponde a parte profana do ritual. Do ponto de vista posicional do ritual, sustentando em Turner (2005), essa hierarquia constituída pelos donos da casa, expectadores e cozinheiros apresenta traços da estrutura social e da forma como esses indivíduos se organizam nessa tradição cultural.

Após a Sussa, os foliões seguiram com o giro da folia pelas casas da redondeza, realizando, segundo a tradição, as performances do "canto para o dono da casa" e da "curraleira", finalizando com a chegada no "pouso da folia". O pouso foi realizado na casa de Irene, uma das filhas dos festeiros. Já estava escurecendo quando os foliões realizaram a performance do "agasalho". Esta possui uma estrutura semelhante à da "despedida", ou seja, uma dupla de guias conduz o cântico seguido por uma dupla de contraguias que os responde, ficando os outros foliões atrás destes. A performance do "agasalho", a partir da análise que realizamos, configura-se como um pedido aos donos da casa para que o Santo adentre ao recinto. No entanto, apesar de ser feito na forma de um pedido, trata-se de uma obrigação, pois os donos da casa irão recebê-lo e cumprir as etapas do processo ritual.

Desse modo, mais uma vez, ao final do cântico, o alfere transfere a bandeira aos donos da casa que a levam a um cômodo privado, onde são feitas as orações de modo particular pelos donos da casa e pelos outros moradores. Percebemos que enquanto esse momento privado ocorria, os foliões se socializavam com os presentes para o pouso da folia, sob a tutela, é claro, do alfere. $O$ objetivo de o alfere estar presente e coordenando todo o processo ritual está relacionado à característica de seu papel social na folia, cujo poder é, inclusive, punitivo.

$\mathrm{Na}$ sequência, foram realizadas as performances do canto para o dono da casa, do bendito de mesa (parte 01 e 02) e da sussa. Com foco nessa constatação, é preciso compreender que essa tradição de folia se altera para atender aos anseios dos sujeitos que the dão identidade. Exemplo disto é o fato de a Sussa compor uma das performances desse ritual, já que esta dança não é conhecida/realizada por outros tipos de folia que são praticadas em Goiás (Brandão, 1981, 1983).

Após a última performance da noite, alguns foliões foram dormir e outros continuaram, como nomearam, a "prosa" com conhecidos. É quando um dos foliões foi visto às carícias com uma mulher por outro folião, que o "dedurou" para o alfere. Começou-se então uma discussão sobre a necessidade ou não de puni-lo por conta da quebra de uma regra, que o colocaria no "rala". Entre os mais velhos, isso não precisaria ser pautado, 
por ser um desrespeito com o santo, mas, para dois foliões mais jovens essa regra deveria ser alterada. De acordo com estes dois foliões, já tinham cumprido sua obrigação com o santo e, portanto, seu comportamento não se configurava como desrespeito ao mesmo. O alfere lembrou-Ihes que essa normativa havia sido informada antes do início da folia e que o folião passaria pelo "rala". Enquanto acontecia essa discussão, que questionava valores referentes à tradição do ritual, outros foliões escolhiam uma pedra áspera para realizar o rala.

Durante a realização do "rala", o folião "paga" sua dívida perante o santo ficando de joelhos sobre uma pedra áspera diante da bandeira. Enquanto o folião reza e pede perdão ao santo por sua falta, os outros foliões, a título de "brincadeira" e para aumentar o sofrimento do colega que está sendo punido, colocou as mãos sobre seus ombros forçando seus joelhos sobre a pedra. Esse ocorrido demonstra a força do polo ideológico na regulação das relações sociais entre os indivíduos pertencentes a essa tradição cultural (Turner, 1988). Apesar da visível revolta e discordância do folião a respeito dessa coerção, ele acabou por aceitar a aplicação do "rala", ficando perceptível sua eficácia simbólica para a contenção desse comportamento indesejável, já que nos dias seguintes esse fato não se repetiu (Mauss, 1974).

Ao amanhecer o dia, os foliões tomaram café da manhã e organizaram a performance da "despedida", que possui a mesma estrutura espacial e organizativa da performance do "agasalho". O que mudou foi seu ato comunicativo, em que nessa performance agradeceram a estadia e pediram desculpas por possíveis "faltas" que tiveram ao permanecerem na casa. É quando o dono da casa entrega para o alfere a bandeira do santo e os foliões se organizam de forma alinhada. Nesse momento, o alfere passa sobre a cabeça de cada um dos foliões a bandeira, indo da esquerda para a direita e da direita para a esquerda. Para finalizar, cada folião beijou a bandeira que, segundo a exegese, esse ato significa o pedido de proteção ao santo para continuarem com a obrigação do ritual. Esse momento foi realizado sob o som da caixa, que estava sendo batida de forma rápida e com uma sonoridade baixa.

O "giro da folia" atendeu a mesma estrutura performática durante todos os outros dias, alterando apenas as rimas construídas sobre o cotidiano nas performances da curraleira. Dada sua importância no processo ritual, consoante à sequência de etapas, pode-se dizer que o "giro da folia" se constituiu como o período liminar do processo ritual, em que transparece uma comunicação extraordinária, se preferirmos, do santo com os sujeitos que compartilham dessa tradição religiosa, sendo possível fazer contato direto com sua divindade de devoção. Isso ocorre devido a bandeira ser o símbolo ritual na sua menor unidade, em que a eficácia na transmissão dos valores sociais é possível devido a liminaridade que o passeio do santo provoca ao girar a folia. Adentraremos agora na análise das performances de entrega da folia, período que classificamos, tomando por referência Turner (2005), como o período de reagregação.

Já estava escurecendo quando os festeiros aguardavam a chegada dos foliões na porteira, local onde se iniciam as performances de "entrega da folia" em sua casa. Foi então que o alfere se direcionou com a bandeira de São Sebastião para Seu Louriano e, parando à sua frente, Ihe fez uma reverência com uma leve flexão de pernas e com os pés em posição anteroposterior. Pode parecer semelhante ao simbolismo presente na performance do "agasalho", mas aqui existe um gesto técnica corporal - que modifica o ato comunicativo, que foi a flexão de pescoço do alfere diante do dono do ritual/ festejo da mesma forma como foi realizada na entrega da bandeira ao alfere antes da "solta da folia". Isso porque estava diante daquele que representava o posto mais alto na hierarquia da folia, pedindo-Ihe permissão para iniciar o ritual de entrega. No entanto, a bandeira foi devolvida ao alfere que só lhe entregaria definitivamente dentro da capela com o término das obrigações dos foliões.

Passado esse momento, todos os foliões se posicionaram atrás do alfere que ficou de frente a um cruzeiro feito de bambu verde em formato triangular. $\mathrm{Na}$ base desse triângulo, tinha três velas que foram acesas quando se ouviu o som da caixa anunciando a chegado dos foliões e simbolizavam a santíssima Trindade. Temos então o início da saudação (1ำ momento que compõe a performance de entrega da folia). Foram entoados três cânticos puxados pelo alfere e seguido pelos foliões sem o uso de instrumentos, em que pediam a São Sebastião permissão para iniciar o ritual de entrega da folia. Foi então que entraram em um túnel feito de diversos arcos enfeitados com papel crepom colorido, localizado entre duas bananeiras paralelas e a capela/rancho feita de piaçaba e troncos de árvores, onde seria feita a reza.

Após a autorização do casal, os foliões entraram no recinto e permaneceram na mesma formação que estavam, em duas colunas paralelas indo desde o altar até a porta de saída. Em volta dessa capela estavam todos os convidados que não faziam parte do grupo familiar e assistiram ao ritual pelas frestas existentes entre as madeiras que formam as paredes da capela. O canto realizado pelos foliões, nesse momento, era de agradecimento por terem chegado para a entrega da folia e estava relacionado ao polo ideológico, pois faziam reverências a São Sebastião (Turner, 2008). Assim terminou o ritual da "saudação".

Nesse momento, se iniciou a reza (2ㅇ momento que compõe a performance de entrega da folia). Aqui, diferentemente do giro da folia, todos os cânticos são puxados pelos guias sem alternância com os contraguias, sendo que a resposta para a frase iniciada pelos guias é feita por todos os foliões. Aqui tivemos quatorze foliões participando e não apenas oito como nas performances anteriores em que revezavam entre si, tendo o alfere à frente segurando a bandeira sobre o altar. Outra diferença em relação às performances do giro da folia é que os 
cânticos agradeciam aos festeiros pelo comprimento de suas obrigações perante o Santo, bem como, dos foliões pela disciplina no comprimento de sua devoção.

Terminado esse agradecimento feito pelos foliões, todos ficam sentados ou ajoelhados dentro da capela e Dona Maria (cunhada de Seu Loro e Dona Dominga) conduz a reza, em que, além da reverência ao Santo, são feitos novos pedidos/promessas para o próximo ano. Em seguida, todos se abraçaram na capela entre si, sendo perceptível a emoção entre os presentes e a capacidade do símbolo ritual de tocar na sensibilidade (Radcliffe Brown, 1973).

Passado esse momento, os membros do grupo familiar distribuíram para todos os presentes velas, feitas, em sua maioria, artesanalmente e algumas de origem industrial, devido ao grande número de pessoas. Esse era o momento clímax do ritual, em que ocorreriam as trocas com o santo e a renovação de laços para o próximo ano (Mauss, 1974). A bandeira é então retirada da vara onde o alfere a conduziu no giro da folia e é entregue para um casal de adolescentes que irá carregá-la nas mãos, estando um ao lado do outro até o momento de ser levantada no mastro.

Temos então o início do levantamento do mastro (3 e último momento que compõe performance de entrega da folia). Um dos foliões começa a tocar a caixa e seus companheiros se reúnem a sua volta entoando o seguinte cântico:

$$
\begin{aligned}
& \text { Viva o capitão do mar } \\
& \text { Viva o povo dessa festa } \\
& \text { Viva o povo da estação (bis) } \\
& \text { Ora beba (bis) } \\
& \text { Mas que São Sebastião (bis) }
\end{aligned}
$$

\section{TRANSCRIÇÃO 01: LEVANTAMENTO DO MASTRO}

Nesse instante, os dois adolescentes que estão com a bandeira começam a caminhar em movimento circular em volta do mastro e da fogueira que está ao centro, seguido dos foliões e das pessoas presentes (aqui a característica polissêmica do símbolo ritual da bandeira fica mais evidente, agindo de forma concomitante, tanto o polo ideológico como o sensorial). Isso porque, no levantamento do mastro temos a dimensão normativa (com a realização de rezas, de pedidos, de promessas, do atendimento de graças etc), seguida da performance da sussa em volta do mastro que é ligada ao polo sensorial (feita com a ingestão de bebidas alcoólicas, danças em pares, sensualidade etc). Durante o giro da folia, isso não ocorria, porque a sussa era uma performance em que não podia ter a presença da bandeira, diferenciando-se, nesse caso, por ser a culminância do ritual da Folia de São Sebastião (Turner, 1988). As luzes presentes no local eram somente as velas, a fogueira e a lua rodeada de estrelas. Aquela performance circular da Sussa em volta do mastro e o semblante de satisfação dos membros da família de Seu Loro e Dona Dominga eram indescritíveis. Dessa forma, termina o "levantamento do mastro" e a Folia de São Sebastião da comunidade.

Esse momento de entrega da folia apresentou-se, como analisado acima, como o período de reagregação (Turner, 2005), no qual os símbolos de maior prestígio entre os participantes do ritual são retomados, demonstrando a capacidade que tem o ritual de Folia de São Sebastião da família de Seu Loro e Dona Dominga em perpetuar as tradições culturais desse grupo familiar. Era visível, no término da performance o sentimento de obrigação cumprida e alegria entre todas as personalidades sociais do ritual. Durante o restante da noite, comemoraram a entrega da folia regada a bastante comida, bebidas e dançaram forró até o dia amanhecer (no sentido literal da palavra). Este é o desfecho do ritual de folia na Comunidade Quilombola Magalhães.

\section{CONCLUSÃO}

Em suma, esta pesquisa de natureza essencialmente etnográfica, caracterizou-se por uma interpretação das performances do corpo-negro-quilombola expressas nos rituais populares da Comunidade Quilombola Magalhães, analisando os aspectos simbólicos que se constroem/ transmitem na tradição cultural em sua dinamicidade.

Como se pôde perceber, a folia de São Sebastião da Comunidade Quilombola Magalhães se constitui como um processo ritual caracterizado pelo significado da dádiva e da construção do corpo-negro-quilombola. O conjunto das obrigações ritualísticas seguidas pelos foliões, demonstram que a folia é uma tradição cultural e contribui para o reforço à identidade coletiva do grupo, tanto do ponto de vista do polo ideológico, quanto do polo sensível. A participação dos foliões, o respeito aos proibitivos sociais, como no caso da relação afetiva que foi punida durante a folia e a peremptória necessidade de manutenção da performance cultural, demonstram o esforço de reagregação de estruturas sociais (predominantes nesse ritual).

A polarização do símbolo da bandeira ocorre, predominantemente, no período liminar de giro da folia através de suas performances. Esses são o do agasalho, o do cântico para o dono da casa, o do bendito de mesa (parte 01 e 02), a sussa, a curraleira e a despedida. As performances do agasalho, do canto para o dono da casa, do bendito de mesa e da despedida atuam predominantemente no polo ideológico, pois reagregam valores, regras, condutas e normas sociais compartilhadas e reafirmadas perante o grupo através do ritual. Já a sussa e a curraleira atuam, com maior predominância, no polo sensorial, no qual prevalecem a satisfação dos desejos e a incitação de transgressões sociais. Por essa estruturação, é possível analisar que as dimensões normativas têm uma predominância no ritual, o que pode ser exemplificado 
no fato de serem realizadas sempre com a presença da bandeira.

Durante a performance de levantamento do mastro fica visível a sensação de pertencimento dos indivíduos àquela tradição cultural. $\mathrm{O}$ símbolo da bandeira, sendo alçado ao alto, expressou o atendimento das graças e promessas de sua família por mais um ano perante sua divindade de devoção. A performance da Sussa à sua volta coroava o clímax de fechamento desse ritual, momento em que a polarização entre a dimensão ideológica e a dimensão sensorial pareceu mais próxima e uma ressignificação da performance da Sussa realizada na presença da bandeira. Fato que não ocorreu na solta e giro da folia, além de uma diferença perceptível, tanto na sonoridade dos instrumentos como no canto realizado.

Em suma, o símbolo ritual da bandeira, sua capacidade de dádiva e de ação sobre a realidade sintetiza a Folia de São Sebastião da Comunidade Quilombola Magalhães, motiva sentimentos coletivos e a estrutura social da comunidade ao passo que se constitui como um ato tradicional e eficaz para o grupo. A bandeira possui uma capacidade multivocacional expressa através de performances magistradas pela sonoridade das violas, das caixas e dos pandeiros. Sendo assim, a folia é uma forma de transmissão de sentidos e significados compartilhados neste grupo familiar, bem como contribui para sua estruturação social e para o reforço ao corponegro-quilombola.

\section{FINANCIAMENTO}

O presente trabalho contou com apoio financeiro do extinto Ministério do Esporte, programa: Esporte e Lazer da Cidade - 1250, ação: 27.812.1250.2426.0001 - Fomento a Pesquisas para o Desenvolvimento de Políticas Sociais do Esporte Recreativo e de Lazer Nacional - REDE CEDES.

\section{CONFLITOS DE INTERESSE}

Os autores declaram não haver conflitos de interesse.

\section{REFERÊNCIAS}

Almeida R. Relatório antropológico de reconhecimento e delimitação do território da Comunidade Quilombo Família Magalhães. Brasília: Instituto Nacional de Colonização e Reforma Agrária; 2007. 136 p.

Brandão C. Sacerdotes da viola: rituais religiosos do catolicismo popular em São Paulo e Minas Gerais. Petrópolis: Vozes; 1981. 274 p.

Brandão C. Estrutura e processos sociais de reprodução do saber popular: como o povo aprende? 2nd ed. Campinas: Vozes; $1983.98 \mathrm{p}$.

Brandão C. A folia de reis de Mossâmedes in De tão longe eu venho vindo: símbolos, gestos e rituais do catolicismo popular em Goiás. Goiânia: Editora da UFG; 2004. 409 p.

Gluckman M. Essays on the ritual of social relations. Manchester: The University Press; 1966. 190 p.

Leach $\mathrm{E}$. Ritualization in man in relation to conceptual and social development. Philos Trans R Soc Lond B Biol Sci. 1966;251(772):403-8. http://dx.doi.org/10.1098/ rstb.1966.0026.

Mauss M. Sociologia e antropologia. 2. ed. São Paulo: Ed. EPU; 1974. Noção de técnica corporal.

Oliveira A. Entre o rio e o mar: práticas corporais e cotidiano na Comunidade Quilombola do Cumbe [tese]. Brasília: Faculdade de Educação Física, Universidade de Brasília; 2018.

Peirano M. A favor da etnografia. Rio de Janeiro: RelumeDumara; 1995. $178 \mathrm{p}$.

Radcliffe Brown A. Estrutura e Função na sociedade primitiva. Petrópolis: Vozes; 1973. 200 p.

Turner V. Schism and continuity in African society: a study of ndembu village life. Manchester: The University Press; 1957. 348 p.

Turner V. Anthropology of the performance. New York: Paj Publ; 1988. $185 \mathrm{p}$.

Turner V. From ritual to theatre: the human seriousness of play. New York: Perform Arts Journal; 1989. 127 p.

Turner V. Floresta de símbolos: aspectos do ritual Ndembu. Niterói: EdUFF; 2005. 488 p.

Turner V. Dramas, Campos e Metáforas: ação simbólica na sociedade humana. Niterói: EdUFF; 2008. 278 p. 